\title{
Dinâmicas de classe média e rebelião social ${ }^{\star}$
}

\author{
Elísio Estanque \\ http://www.ces.uc.pt/investigadores/cv/elisio_estanque.php \\ Pesquisador do CES - Centro de Estudos Sociais e professor da \\ Faculdade de Economia da Universidade de Coimbra
}

\section{Introdução}

O presente texto surge na sequência de um conjunto de estudos que tenho vindo a desenvolver em torno da questão da "classe média"1 e sua possível relação com as recentes vagas de movimentos sociais e manifestações, quer na Europa do Sul quer no Brasil, em especial no ano de 2013. As demarcações sociais e de classe possuem, sem dúvida, poderosos fundamentos socioeconómicos e disso procurarei dar conta neste texto. As lógicas e divisões classistas operam em larga medida através de mecanismos de poder simbólico que incidem no sub-consciente (coletivo e individual) e talvez isso ajude a explicar por quê a "classe-para-si" é mais uma narrativa do que uma realidade substantiva. Mas para a reflexão aqui em causa interessa, antes do mais, questionarmo-nos acerca do modo como os recursos económicos e educacionais, por exemplo, são incorporados por pessoas

\footnotetext{
* O presente paper beneficiou da bolsa FAPESP processo $n^{\circ}$ 2012/11670-4 - Visitante do Exterior, no âmbito do qual desenvolvi atividades de pesquisa junto do CESIT/IE e do Dpt. de Sociologia do IFCH da UNICAMP. Contém passagens de uma publicação em livro (em preparação) sob o título A Questão da Classe Média: meritocracia ou rebelião social? (Editora da Unicamp, previsto para 2015).

* Possui doutorado em Sociologia pela Universidade de Coimbra. Licenciatura em Sociologia pelo ISCTE-Instituto Universitário de Lisboa. Docente da FEUC e investigador permanente do Centro de Estudos Sociais. É co-coordenador dos Programas de Mestrado e Doutoramento em Relações de Trabalho, Desigualdades Sociais e Sindicalismo ministrados na FEUC e no Centro de Estudos Sociais (CES) e professor da Faculdade de Economia da Universidade de Coimbra. http://www.ces.uc.pt/ investigadores/cv/elisio_estanque.php
}

concretas ao longo das suas trajetórias de vida e como se estruturam diferenças, segmentações e conflitos entre conjuntos sociais aparentemente próximos no volume de "riqueza" que possuem? Qual a relação entre o enquadramento objetivo numa dada condição ou estatuto social e a sua identificação individual, corporativa, coletiva ou geracional? Que significado podemos atribuir hoje ao papel da classe média, num momento em que muitos reconhecem a sua fragilidade $e$ declínio, como acontece nos países do sul da Europa?

Na era pré-industrial, a ideologia liberal e burguesa que impulsionou o capitalismo emergente assumia-se como o lubrificante ideal para levar por diante a promessa de um crescimento económico infinito tendo no horizonte o bem-estar geral. Segundo os valores do liberalismo triunfante, as recompensas obtidas através do trabalho assegurariam a integração do indivíduo, ou seja, a dedicação, o talento, a iniciativa e o aperfeiçoamento profissional seriam reconhecidos e recompensados pela sociedade. O crescente reconhecimento da atividade do trabalho caminhou de par com a primazia da ideia de "negócio" - uma herança da ética calvinista que abriu caminho ao fim do regime medieval - que, a partir do século XVIII passou a ser considerado o principal meio de angariação de riqueza, status e poder. A visão sobre a classe de lazer de que falava Thorstein Veblen, pressupunha que a velha aristocracia e a nova burguesia nascente se deveriam resguardar de exibir a sua sumptuosidade para evitar a inveja dos povos, o que denuncia a convicção de que

\footnotetext{
${ }^{1}$ Veja-se sobretudo Estanque, 2003 e 2012.
} 
haveria uma relação direta entre a ostentação da riqueza e a ocorrência de revoluções.

\section{O significado social do trabalho assalariado}

A capacidade integradora do sistema capitalista traduzia-se não apenas nos estímulos materiais e salariais, mas também nas diversas formas de reconhecimento e respeito, estimulando a motivação e o sentido de realização pessoal. O trabalho tornou-se uma atividade digna de respeito e por isso merecedora de recompensas simbólicas e materiais, isto é, de admiração e de um salário decente. Se nada mais existisse a prová-lo, lá estava a nova classe média assalariada, boa parte dela descendente de famílias de trabalhadores manuais, para ilustrar esse glorioso mundo de oportunidades. Porém, essa é apenas uma parte da história, a parte contada pelos americanos, pois, na Europa a odisseia social foi bem mais complexa e conflitual. Por outras palavras, a sucessão de lutas e conflitos protagonizados pela classe trabalhadora europeia - que mais tarde daria lugar ao compromisso histórico e ao Estado providência -, seriam como que "esquecidos" pela América do Norte, onde a ideologia liberal e a impressionante força do mercado apagaram, em larga medida, todo esse legado. Com efeito, do outro lado do Atlântico-Norte, a mentalidade triunfante continuou a insistir na ideia de que o esforço e a dedicação recompensam os mais talentosos e, acima de tudo, os que se revêem no status quo vigente.

É a promessa do enriquecimento e do Eldorado, com um profundo significado social ao longo do século XIX, que dá expressão aos processos de mobilidade social entendidos nos EUA segundo uma ótica individual. Todavia, a apologia do individualismo não era alheia ao "perigo" da conflitualidade. Alexis de Tocqueville, considerando que as revoluções se destinam em geral a consagrar ou a destruir a desigualdade, sustentava que "ou os pobres tentam tomar os bens dos ricos ou os ricos tentam aguilhoar os pobres", concluindo que numa sociedade em que cada um tenha algo a guardar e pouco a tomar, será difícil a ocorrência de revoluções violentas. Daí resulta que nas sociedades democráticas, em comparação com o Antigo Regime, os pobres seriam em pequeno número e, além disso, não estariam ligados por laços de uma miséria irremediável e hereditária, enquanto os ricos, além de pouco numerosos, não permitiriam que os seus privilégios atraíssem os olhares, como acontecia antigamente com a riqueza fundiária. Isto é, os ricos não constituiriam uma classe à parte, que facilmente pudesse ser despojada pelos pobres. Entre estes dois extremos, adianta Tocqueville, "acha-se uma multidão inumerável de homens quase idênticos que, sem serem precisamente ricos ou pobres, possuem bens suficientes para desejar a ordem, mas não os têm em demasia para suscitar a inveja". O espírito empreendedor atribuído à pequena burguesia proprietária do século XIX, sobretudo no contexto dos países anglo-saxónicos, foi descrito pelo autor nos seguintes termos: "Sem dúvida que não vivem satisfeitos, mas mantêm com ardor inigualável o desejo de enriquecer, embora esse desejo tenda a permanecer dentro dos limites necessários, porque o facto de viverem numa situação de relativo conforto, que é tão afastada da opulência como da miséria, leva-os a atribuir aos seus bens um preço imenso (...). Como estão ainda muito próximos da pobreza, vêem de perto os seus rigores, e temem-nos; entre ela e estes mais não há que um pequeno património sobre o qual fixam imediatamente os seus temores e as suas esperanças. A cada instante, interessam-se primeiro pelos cuidados constantes que ele thes dá e ligam-se-lhes cada vez mais pelos esforços diários que fazem para o aumentar. A ideia de ceder a menor parte dele é-lhes insuportável e consideram a sua perda como a última das infelicidades" (Tocqueville, 1988: 272). O trabalho e a própria ética profissional, associados a uma "natural" adesão dos indivíduos aos valores do sistema social geral, proporcionam a consolidação de um modelo de sociedade integrada e dinâmica, na qual as desigualdades acabam por funcionar como fatores de estímulo e de disputa pelas posições mais aliciantes. De acordo com esta concepção "positiva" e funcionalista, a classe média assalariada - e o seu esperado crescimento - seria a consequência natural de uma sociedade que, justamente por causa do papel crescente do mercado e da racionalidade, caminhava para um sistema meritocrático, capaz de garantir a harmonia - talvez imperfeita, porque os "desvios" à norma dominante sempre foram reconhecidos

148 Emancipação, Ponta Grossa, 14(1): 147-159, 2014. Disponível em <http://www.revistas2.uepg.br/index.php/emancipacao> 
- entre duas dimensões justapostas: de um lado, o carácter integrado do sistema sociocultural em busca de um aperfeiçoamento permanente; e do outro, o conjunto dos indivíduos agindo livremente e concorrendo uns com os outros no âmbito do mesmo "sistema integrado de valores e normas" em busca de reconhecimento e prestígio social ${ }^{2}$.

Trata-se de uma concepção de sociedade que a toma como se fosse um organismo vivo, sujeito a uma hierarquia de funções e que ganharia eficácia com base na conjugação entre os princípios da mobilidade social e da meritocracia. As recompensas obtidas, uma vez conquistada uma dada posição no campo profissional, por exemplo, dependeriam da sua importância funcional (para o sistema) e da escassez de pessoal em condições de preencher essa função, ou "papel" a ela vinculado. Dependendo do nível de congruência entre o mérito e as exigências requeridas, o papel-status associado à respetiva função seria merecedor de respeito, dignidade e remuneração compatíveis. Assim, as oportunidades derivam do mérito demonstrado e os indivíduos serão estimulados a competir pelas posições desejáveis, de acordo com as suas qualificações e talento. Ora, as posições sociais disponibilizadas pelo sistema em número suficiente e, ao mesmo tempo, suficientemente apetecíveis para se tornarem socialmente relevantes são posições de classe média. Por outras palavras: trata-se agora já não das classes médias proprietárias do século XIX mas sim das novas categorias profissionais arrastadas pelo progresso técnico e pelo aumento da burocracia administrativa, os colarinhos brancos (white collars ou black coated workers) ${ }^{3}$. Principalmente desde meados do século XX, esta classe passou a ser vista como correspondendo aos diversos sectores da força de trabalho que não fazem parte nem dos colarinhos azuis (blue collars) como a literatura consagrou a velha classe operária manual, nem, evidentemente, dos estratos superiores da sociedade. Assim, a classe média

\footnotetext{
2 Perspetivas desenvolvidas por sociólogos americanos como Talcott Parsons e Davies \& Moore.

${ }^{3}$ Os colarinhos azuis referem-se aos trabalhadores manuais, enquanto os colarinhos brancos (por vezes também identificados como os ternos escuros) se referem aos empregados administrativos e dos escritórios.
}

refere-se a camadas socioprofissionais muito diversas, como os empregados de escritório, os funcionários, burocratas e tecnocratas dos sectores público e privado, professores, médicos, profissões técnicas, quadros intermédios, trabalhadores qualificados, etc. Trata-se não de uma classe em sentido rigoroso, mas tão-só de uma mancha, algo nebulosa e internamente diversificada, que se situa algures entre as elites e o povo ou, se preferirmos, entre a classe dominante e os trabalhadores manuais.

Conduzidas essencialmente por autores americanos, as análises funcionalistas pretenderam confirmar teórica e empiricamente o carácter universal das desigualdades, a sua inevitabilidade e até a sua necessidade. Os estudos abrangiam as mais diversas sociedades, não se limitando aos Estados Unidos da América. Partindo do princípio da universalidade da estratificação, admite-se, contudo, que cada sociedade desenvolve estruturas particulares de desigualdade, sendo estas "necessárias" na medida em que, como atrás se disse, estimulam e motivam os indivíduos a alcançar os lugares mais atrativos. O importante aqui a reter é, por um lado, o pressuposto do comando do mérito e, por outro, a ideia implícita - na verdade tornada ideologia - de que, com a crescente evolução económica e tecnológica, as sociedades passariam paulatinamente de modelos em pirâmide aguçada (isto é, típicas de sociedades pré-industriais e de regimes autoritários), para estruturas estratificacionais tendencialmente em losango (isto é, típicas sociedades de classes médias e de regimes democráticos avançados).

Advogando, naturalmente, uma grande diversidade de modelos de sociedade, questiona-se os limites da (maior ou menor) amplitude da especialização de papéis e suas implicações na estrutura geral da estratificação. Estas correntes tomaram como objetos de análise desde os kibutz israelitas às comunidades de diversas regiões e Estados americanos e até o próprio modelo soviético. Nas coletividades de Israel, onde se pretendia reduzir ao mínimo a desigualdade, concluiu-se que a rotatividade de posições no trabalho foi um dos meios para conter a diferenciação social, pelo que era comum criar horários reduzidos ou estimular a emigração parcial dos membros que ocupavam categorias profissionais mais baixas, de modo a 
que, noutros enquadramentos, pudessem ocupar posições mais elevadas.

\section{Do funcionalismo ao marxismo}

No século XIX a temática da classe média revestia-se de contornos bem diferentes daqueles que viria a assumir mais tarde, com a emergência das novas categorias de trabalhadores assalariados, em especial no velho continente. Em todo o caso, a articulação que desde sempre se estabeleceu entre os estratos intermédios e a questão da luta de classes - ou, se quisermos, da conflitualidade social - é um assunto que permanece atual até aos dias de hoje. Com efeito, este fenómeno tornou-se, ao longo do século $\mathrm{XX}$, um dos pontos de maior discórdia entre os dois principais paradigmas, e isto porque essas perspetivas transportavam representações contrárias quanto às virtudes e defeitos do modelo de sociedade em vigor. Os estudos de Marx e de Weber não deixam de evidenciar a dificuldade de separar a análise sociológica do seu voluntarismo e filiação ideológica: se, para Marx, a classe média era a negação mais palpável da sua tese da dicotomia das classes (as duas classes antagónicas), para Weber, as classes médias eram a prova da superioridade racional de um sistema capaz de reconhecer o mérito e oferecer oportunidades aos mais talentosos. E a guerrilha teórica prolongou-se por todo o século XX. Enquanto weberianos e funcionalistas acentuavam o princípio da liberdade, dos direitos individuais e da propriedade privada, colocando o sistema social e o mercado como principais fatores de regulação e de progresso, os marxistas - desde os autores da Escola de Frankfurt ${ }^{4}$, a Gramsci, Rosa Luxemburgo, Lukács, etc. - davam largas à sua crítica radical ao capitalismo, mas omitiram enquanto puderam o significado sociológico

\footnotetext{
${ }^{4}$ Constituída por um conjunto de intelectuais, sociólogos e filósofos que perfilhavam o pensamento crítico, inspirado em Marx, mas que no início dos anos trinta do século $X X$ se demarcaram do modelo soviético e da ortodoxia marxista, ao mesmo tempo que procuraram desenvolver uma teoria critica atualizada do capitalismo e do regime nazi então emergente. Criaram inicialmente o Instituto para Pesquisa Social de Frankfurt, sediado nessa cidade alemã, embora mais tarde muitos destes autores se tenham refugiado nos Estados Unidos (e, durante algum tempo, o próprio Instituto). Alguns dos nomes mais conhecidos deste grupo foram Max Horkheimer, Theodor Adorno, Herbert Marcuse, Erich Fromm; e, numa segunda fase, também nomes como Haxel Honneth e Jürgen Habermas.
}

da mobilidade social e da nova classe média assalariada. $O$ enquadramento político em que se movia a maioria dos pensadores marxistas que abordaram estes temas impediu-os de os interpretar em toda a sua profundidade. Era-lhes difícil reconhecer o significado dos novos empregos qualificados enquanto expressão de uma sociedade de bem-estar no quadro do sistema económico dominante. Para o marxismo, o aumento do poder de compra dos trabalhadores e o triunfo do Estado-providência foram, pelo contrário, interpretados como fruto de uma massificação consumista promovida pelo mercantilismo e o poder do capital, cujos efeitos perniciosos se traduziam na crescente alienação e conformismo dos trabalhadores, embora na prática - nas sociedades industrializadas do mundo ocidental - se assistisse a uma tendência de mobilidade social ascendente que negava a visão dicotómica da luta de classes $^{5}$. Note-se, todavia, que essa mobilidade nunca foi expressão pura do "mérito" individual, ao contrário da visão liberal e positivista.

Foi já no pós-II Guerra, e perante o cada vez maior descrédito do modelo soviético, que começaram a proliferar entre os marxistas novos estudos virados para a análise da estrutura das classes nas sociedades industrializadas, dando lugar a obras de elevada elaboração conceptual e apoiadas numa sofisticação técnica e metodológica até então inexistente. Nomes como Louis Althusser e Étienne Balibar, Nicos Poulantzas, Daniel Bertaux, Erik Wright, etc., impulsionaram um conjunto de pesquisas que conjugaram, pela primeira vez, o desenvolvimento simultâneo da reflexão teórica e da análise empírica em sociedades concretas. Mas, apesar da vitalidade do debate, a classe permaneceu um conceito essencialmente contestado. Embora no campo do marxismo as preocupações se dirigissem mais para a crítica do papel político da classe média enquanto fator apaziguador dos conflitos de classe, a sua influência também se fez sentir nas abordagens críticas da mobilidade, onde se destacou a chamada teoria da reprodução,

\footnotetext{
${ }^{5}$ Ou seja, o ideal marxista-leninista da luta entre as duas classes "antagónicas", a burguesia e a classe operária, o qual foi durante décadas uma pedra basilar da visão determinista desta ideologia política, por vezes designada por teoria marxista do "materialismo histórico".
} 
direcionada para a análise da educação mas com uma óbvia ligação à temática da mobilidade social e da recomposição das classes. De resto, nomes como Bourdieu e Passeron (1978), que inauguraram essa discussão, ainda que assumindo uma ligação teórica ao marxismo, acabaram por ser alvo da crítica dos seus pares devido à excessiva ênfase que colocaram na capacidade reprodutiva do sistema educativo e da cultura dominante no capitalismo.

As tentativas de atualização dos legados de Marx e de Weber na segunda metade do século passado, resultaram em combinações teóricas que dificilmente se encaixam num ou noutro desses dois paradigmas. Aquilo que os weberianos designaram de "classe média" surgia na terminologia marxista da época com outras designações, tais como "nova pequena burguesia", "pequena burguesia urbana", "nova classe operária", etc. Segundo Nicos Poulantzas, os novos sectores assalariados que se vinham juntando ao reforço do Estado, da modernização técnica e da burocracia nas empresas - a dita "classe média" - forneceram uma base social extraordinariamente importante para a reprodução do capitalismo. Categorias profissionais em crescimento, tais como professores, técnicos, funcionários, gestores de topo, quadros e profissionais de saúde ou da administração pública, funcionaram como uma imensa plataforma de amortecimento da luta de classes ou, dito de outro modo, constituem o principal meio de cooptação ou de emburguesamento da classe operária e dos seus descendentes, afastando-os assim dos caminhos da atividade sindical e política. Esta concepção inventariou alguns dos principais atributos apontados às camadas profissionais pertencentes à classe média, nomeadamente a sua proximidade com o poder dos dirigentes, a sua orientação individualista para a carreira, o seu seguidismo em relação às chefias e a sua predisposição consumista. Tais atributos justificam a designação que alguns dos autores atrás referidos tentaram colar à classe média - a nova pequena burguesia.

Vale a pena ainda referir o contributo de Erik Olin Wright, que, apesar de partilhar muitas destas preocupações e conceitos (comuns ao campo marxista), elaborou um modelo analítico que trata as diversas categorias da classe média como movidas não por uma adesão plena ao sistema dominante mas por contradições de poder, formas de controlo e de qualificação que tentam monopolizar. Wright tinha teorizado inicialmente sobre estas camadas intermédias, classificando-os como lugares contraditórios nas relações de classe, evoluindo daí para um modelo que recupera (de Marx) o conceito de exploração e conjuga-o com o papel do mercado concorrencial (de Weber). Com isso contribuiu para mostrar o carácter dinâmico e contraditório das relações sociais entre diferentes categorias socioprofissionais no seio da classe média. $\mathrm{Na}$ mesma linha, várias situações de classe podem considerar-se "exploradoras" segundo certos critérios ${ }^{6}$, por exemplo, o caso de grupos qualificados que beneficiam dos seus diplomas escolares (quando a oferta escasseia), mas são "exploradas" segundo outros critérios, por exemplo, naqueles casos em que não possuem qualquer autonomia nem autoridade no exercício da profissão, em comparação com outros que as possuem em abundância (Wright, 1989).

\section{Classe média, integração e dissidência}

Pode dizer-se, portanto, que a conflitualidade (latente ou manifesta) está presente em todas dimensões da sociedade, inclusive entre segmentos distintos no seio da "classe média". Na sua obra Sociologia de lo Posible, José Maria Maravall (1972) sustentava que numa trajetória ascensional as expectativas vão sempre um degrau adiante da posição do indivíduo, mas se ocorrer uma situação em que, de repente, a escada termine abruptamente e se caia num declive, a intensidade da frustração dispara, porque as expectativas continuaram a crescer, em contraste com a sua - objetiva - degradação abrupta. É o caso de quem investe tudo o que tem num curso superior ou numa formação avançada

\footnotetext{
${ }^{6}$ Note-se que a "exploração" é aqui entendida como uma relação social entre dois ou mais indivíduos ou grupos em que um deles está em condições de beneficiar a expensas do esforço ou privação de outros. Em sentido lato, pode falar-se em exploração de status quando um indivíduo tira vantagem do facto de possuir um determinado título que é muito raro. Se todos os trabalhadores possuíssem um grau de licenciatura, por exemplo, não seria possível alguém beneficiar no mercado de trabalho devido a esse critério, ou seja, se um diploma é escasso e tem muita procura adquire maior valor. Por outras palavras, a escassez, a concorrência e o mercado interferem nos mecanismos da desigualdade e, num certo sentido, da exploração.
} 
para conseguir uma promoção e, quando está à beira de conseguir esse objetivo depara-se com o desemprego. Quando o sonho mais colorido se revela, afinal, não passar de uma miragem, só pode dar lugar à decepção e à revolta. Como é natural, tais circunstâncias favorecem a insatisfação e a ocorrência de conflitos, que podem adquirir um impacto político se isso atingir um volume significativo de pessoas ou uma geração inteira. E, como sabemos, é a partir dessa conjugação entre expectativas e desilusões (ou sentimentos de realização) que, das duas uma, ou pode reforçar-se a coesão da sociedade ou explodir a instabilidade social. Um cenário que, não sendo estranho à classe média, pode voltar a ser reeditado no futuro, na linha do que ocorreu na década de 1960 quando novos segmentos da classe média assalariada, em aliança com a juventude universitária integrou do movimentos sociais que contribuíram para importantes viragens socioculturais no mundo ocidental (Parkin, 1968; Barker, 2008). Conflito e diálogo, ação coletiva e iniciativa individual resultam em processos complexos de mudança e readaptação, estritamente vinculados à clássica tensão entre a força do mercado e a regulação estatal. É nesse sentido que o chamado radicalismo de classe média, pensado por referência aos movimentos estudantis nas décadas 1960-1970 (Estanque e Bebiano, 2007) abriu um novo olhar sobre estes segmentos, e questionou alguns dos velhos argumentos da velha vulgata marxista quanto ao "individualismo" e "emburguesamento", os anátemas lançados na época contra a classe média.

Com efeito, os movimentos sociais daquele período revelam ao mesmo tempo o poder uniformizante (e alienante) do consumismo e o potencial de dissensão e revolta dos filhos dos segmentos acomodados ao statu quo dos sixties. O paradoxo tornou-se evidente: por um lado, a ideia de que a classe média era, acima de tudo, caracterizada pela sua boa vontade cultural, vocacionada para mimetizar os hábitos e modalidades de gosto das elites, propensa ao individualismo e à adesão à ordem vigente; por outro, a emergência de novas modalidades de irreverência juvenil vinculadas à cultura estudantil e aos valores pós-materialistas (Eder, 2001).

Pode dizer-se, portanto, que a dimensão do consumo não se limitou a mostrar uniformidade, mas também novas demarcações sociais, nomeadamente no campo dos estilos de vida entre diferentes camadas sociais divididas por diferentes tipos de "capitais" (propriedade económica, recursos educacionais, capital social) que Ihes redefiniam os seus estatutos. Isto liga-se ao que Pierre Bourdieu (1979) designou como a lógica da distinção. Pode imaginar-se, por um lado, a elite a exigir o monopólio do gosto distintivo e a anular as tentativas de usurpação levadas a cabo pelos estratos intermédios que disputam recursos e oportunidades de ascensão; e, por outro lado, as investidas destes para subir, em busca da proximidade, da partilha de um espaço contíguo que é muitas vezes vivida como sinal de sucesso na assimilação do gosto estético do grupo-alvo. A ânsia de apropriação, porém, dá lugar a representações onde é fácil confundir a imitação com o original. Sendo a cópia sempre imperfeita, o que as classes médias podem usurpar às elites acaba muitas vezes por reforçar o poder simbólico dos grupos dominantes, uma vez que estes, com as suas táticas de fuga à "vulgaridade", sempre conseguem o exclusivo e, não poucas vezes, fazem gala em ridicularizar a plebe (leia-se a classe média ou a nova pequena burguesia) na sua postura desajeitada e "pequena", em contraste com a sua ambição desmedida. A verdadeira elite reserva para si o exclusivo de um espaço, de um estilo, de uma moda, de uma linguagem, etc., que resiste a deixar-se "contaminar" pelos estratos inferiores, obrigando estes a consumir a aparência, a versão superficial, a opereta em vez da ópera, a comédia em vez do teatro clássico, a música ligeira em vez da "grand musique". Os segmentos de "novos ricos"7 e mal acomodados da classe média fornecem bons exemplos de orientações subjetivas que P. Bourdieu cunhou de boa vontade cultural, típica de categorias sociais em ascensão. A pouca familiaridade com esses meios traduz-se numa grande ansiedade por mostrar um conhecimento enciclopédico que recompense o seu défice de erudição, é bem um exemplo das lutas simbólicas pela diferenciação

\footnotetext{
${ }^{7}$ Seja qual for o campo onde operam, a economia e os clubes exclusivistas que famílias empresariais com escassas bases culturais, a política, no seu enquadramento institucional ou mesmo o campo académico promovem ilustram a situação de subsegmentos particulares de "classe média" que se debatem pela consolidação de um estatuto ainda mal definido.
} 
e apropriação de status que acompanham as práticas desses grupos.

Estudos empíricos centrados em países europeus e nos Estados Unidos da América mostraram que os processos de mobilidade, além de serem sobretudo intergeracionais e de curto alcance, funcionam segundo movimentos de oscilação para baixo e para cima - as zonas de amortecimento - em que os processos de ascensão nunca são lineares. Importa portanto não esquecer que a mobilidade social (falo aqui sobretudo dos fluxos ascendentes) é sempre marcada por obstáculos, mesmo que alternados por "trampolins" que ajudam a transpô-los, e às vezes entra em retrocessos irremediáveis. Como na subida de uma montanha íngreme, quanto mais nos aproximamos do topo mais difícil e doloroso é dar o passo seguinte. Apesar do viés eurocêntrico que esteve na origem destas teorias, as suas repercussões na sociedade brasileira são bem visíveis na atualidade.

\section{Estruturas de classe e conflitualidade}

$\mathrm{Na}$ verdade, questões correlatas da discussão sobre a mobilidade social e a meritocracia, como sejam a interposição de renovadas barreiras e segmentações de classe, têm vindo a ganhar relevo nas últimas décadas, pois os mecanismos de fechamento têm-se tornado extremamente poderosos, sobrepondo-se de forma clara ao critério do mérito. Lembrando um conhecido título de Erik Olin Wright ${ }^{8}$, importa ter presente que a classe conta. $\mathrm{E}$ vale a pena reconhecer também que o mérito conta. Mas, é preciso acrescentar, retomando uma ideia de R. Dahrendorf, que "mesmo aqueles (poucos) que chegam às elites pelo seu mérito e talento, fecham as portas atrás de si logo que tenham alcançado o seu status. Os que lá chegaram por 'mérito' passam a querer tudo o resto - não apenas poder e dinheiro mas também a oportunidade de decidir quem entra e quem fica de fora" ${ }^{\prime \prime}$. Dito de outra forma, o mérito conta, mas não se pense que as oportunidades de ascensão dependem

\footnotetext{
${ }^{8}$ Class Counts: comparative studies in class analysis, Cambridge University Press, 1997.

${ }^{9}$ Artigo de opinião de Ralf Dahrendorf, publicado no jornal Público sob o título "Ascensão e queda da meritocracia", em 02/05/2005, p. 7.
}

exclusivamente ou sequer principalmente do critério meritocrático. $\mathrm{O}$ crescimento da classe média assalariada nas sociedades industrializadas derivou de ambos os processos, pelo que as teses do "individualismo empreendedor", de um lado, e da luta de classes, associada ao surgimento dos novos movimentos sociais, de outro lado, podem ser tomadas como as duas faces do mesmo processo de recomposição profunda da estrutura das classes.

O historiador brasileiro Valério Arcary, um reconhecido especialista em revoluções, afirmou em entrevista recente que, para compreendermos os comportamentos coletivos e a contestação social, "o elemento a ser considerado, e mais importante [é a] a memória político-social da história recente. Naquelas sociedades em que, no período histórico anterior, os trinta anos do passado recente, a população viveu a experiência de crescimento económico, existiu alguma mobilidade social, uma parcela da classe operária e a maioria da classe média conseguiram acesso a casa própria, os ajustes económicos na forma de ataques sociais impiedosos manifestam-se como uma hecatombe inesperada. Nestas circunstâncias, a fúria popular tende a ser proporcional à desilusão. O potencial de explosividade é mais intenso" (Arcary, 2013).

O crescimento da classe média assalariada nas sociedades industrializadas derivou de ambos os processos, pelo que as teses do "individualismo empreendedor", de um lado, e da luta de classes, associada ao surgimento dos novos movimentos sociais, de outro lado, podem ser tomadas como as duas faces do mesmo processo de recomposição profunda da estrutura das classes. O historiador brasileiro Valério Arcary, um reconhecido especialista em revoluções, afirmou em entrevista recente que, para compreendermos os comportamentos coletivos e a contestação social, "o elemento a ser considerado, e mais importante [é a] a memória político-social da história recente. Naquelas sociedades em que, no período histórico anterior, os trinta anos do passado recente, a população viveu a experiência de crescimento económico, existiu alguma mobilidade social, uma parcela da classe operária e a maioria da classe média conseguiram acesso a casa própria, os ajustes económicos na forma de ataques sociais impiedosos manifestam-se como uma 
hecatombe inesperada. Nestas circunstâncias, a fúria popular tende a ser proporcional à desilusão. O potencial de explosividade é mais intenso". (Arcary, 2013).

Conflito e diálogo, ação coletiva e iniciativa individual resultam em processos complexos de mudança e readaptação, estritamente vinculados à clássica tensão entre a força do mercado e a regulação estatal. É nesse sentido que o chamado radicalismo de classe média, pensado por referência aos movimentos estudantis dos anos sessenta (Parkin, 1968; Barker, 2008; Estanque e Bebiano, 2007) abriu um novo olhar sobre estes segmentos, e questionou alguns dos velhos argumentos da vulgata marxista quanto ao "individualismo" e "emburguesamento" os anátemas lançados contra a classe média na sua suposta "essência". Essa é, aliás, a premissa que o presente texto procura combater: a ideia de que a classe média é, acima de tudo, caracterizada pela sua boa vontade cultural, que tenta mimetizar os hábitos e modalidades de gosto das elites, definida pelo seu individualismo e por uma inequívoca adesão à ordem vigente.

Segundo Slavoj Žižek, podemos conceber as revoluções como uma solução universal, ou sistémica, para problemas particulares, ou seja, os bloqueios "locais" podem revelar ou exigir ruturas sistémicas como condição para que uma saída local seja plausível. Para ele, "a diferença entre um período reformista e um período revolucionário é que no primeiro a revolução global continua a ser um sonho que, na melhor das hipóteses, sustenta as nossas tentativas para aprovar alterações locais - e no pior dos casos impede-nos de concretizar mudanças reais -, ao passo que uma situação revolucionária surge quando se torna claro que apenas a mudança global radical pode resolver os problemas particulares" (Žižek, 2013: 101). Ora, seguindo o princípio marxista de "totalidade" somos levados a pensar o capitalismo global de hoje como "um processo complexo que afeta diversos países de maneiras variadas, e o que unifica tantos protestos na sua multiplicidade é que eles são todos reações contra as múltiplas facetas da globalização capitalista" (Idem: 103). Porém, os levantamentos sociais aqui em analise estão longe de se poderem confundir com revoluções (pelo menos se estas forem entendidas com esse sentido eminentemente político), muito embora em alguns casos da chamada Primavera Árabes (Tunísia, Egito, Líbia) tenham ocorrido mudanças de governo devido ao poder das rebeliões sociais. Aquilo que uniu este ciclo de mobilizações foi acima de tudo o facto de nenhuma delas poder ser reduzida a uma única questão e todas se terem apoiado numa sobreposição de preocupações sociais (cf. Giovanopoulos e Dalakoglou, 2011).

De formas muito diversas, a combinação de uma súbita degradação das condições materiais da vida de uma parte significativa da população, aliada à crise de legitimidade das instituições políticas, é o pano de fundo decisivo, situado para além da esfera política. Por outras palavras, como ensinou o próprio Marx, a chave está na esfera "apolítica" das relações sociais: "desde o mercado até à família, em que a mudança necessária, se quisermos uma melhoria efetiva, não é a reforma política, mas a transformação nas relações sociais 'apolíticas' de produção" (Marx, apud Žižek, 2013: 106). Este ciclo de protestos a que o mundo assistiu nos últimos anos, iniciado na Europa do sul e, logo incendiado pela Primavera Árabe, foi simbolicamente marcado pela imolação de um jovem tunisino em dezembro de 2010. Desde então a sua propagação atingiu diferentes países e regiões do globo. Apesar das particularidades de cada caso, as suas contaminações recíprocas foram inegáveis. Na primeira concentração na Praça Tahrir no Cairo os manifestantes gritaram "Tunísia é a solução". Nos EUA, a primeira convocação Online (de julho de 2011) que levaria ao movimento Occupy Wall Street, clamava contra o poder do capitalismo financeiro perguntando "estão prontos para um momento Tahrir?". Nas mobilizações europeias a silenciada "Revolução Islandesa" funcionou como um exemplo de resistência cidadã no ataque ao setor financeiro: "menos Irlanda, mais Islândia", ou "somos todos gregos" foram frases exibidas em cartazes de manifestantes portugueses em 2011 e 2012. Essas manifestações conseguiram mudanças institucionais concretas em diversos países, levando à queda de governos e, em alguns casos, impondo transformações canalizadas pelo e para o Estado, tornando-se exemplos inspiradores porque mostraram que era possível.

O papel dos meios audiovisuais e da internet, ai difundirem em tempo real as

154 Emancipação, Ponta Grossa, 14(1): 147-159, 2014. Disponível em <http://www.revistas2.uepg.br/index.php/emancipacao> 
espetaculares imagens de confrontos entre manifestantes e forças policiais contribuíram decisivamente para maximizar o potencial mimético e a sua propagação transnacional. Manuel Castells, o primeiro sociólogo a estudar o fenómeno, apontou alguns dos fatores da emergência deste tipo de mobilizações, sugerindo três elementos essenciais (referindose ao caso tunisino): (1) a existência de um contingente de jovens qualificados e desempregados, capazes de liderarem a revolta dispensando as tradicionais estruturas de poder e representação; (2) a presença de uma cultura de ciberativismo muito forte, que permitiu criar um espaço público crítico do regime ditatorial $e$ com autonomia relativamente à repressão do Estado; e (3) uma taxa de difusão do acesso à Internet significativa, seja em postos domésticos, seja em cibercafés ou espaços educativos, o que, combinado com a existência de sectores juvenis com altas qualificações e sem emprego, fez da juventude um ator central da revolução. Para este autor, as redes sociais criaram, de facto, novas modalidades de ativismo onde o carácter híbrido entre o face-a-face e o espaço virtual se revelou um traço fundamental. Por outras palavras, não se tratou de um processo de mobilização que dependeu apenas do espaço virtual. O importante é que a ligação entre comunicação livre no Facebook, no YouTube e no Twitter e a ocupação do espaço urbano criaram um espaço público híbrido, uma esfera "virtual-real" de construção de liberdade que se expandiu da rebelião tunisina a uma variedade de países e continentes (cf. Castells, 2013: 25-31).

É possível, para além disso, pensar num outro conceito de "movimento", neste caso entendido como sinônimo de forças mais gerais que promovem as grandes tendências de mudança social. Partindo de uma interpelação a Karl Polanyi (2001), contra a sua abordagem da transformação no capitalismo moderno a partir do conflito entre a mercantilização e a proteção social, Nancy Fraser apresenta-nos um triplo movimento marcado pela ambivalência e concebido com base em zonas de tensão e conflito entre três forças: 1) os promotores da mercantilização; 2) os adeptos da proteção social; e 3) os partidários da emancipação. "A proteção social é frequentemente ambivalente, ao mesmo tempo que alivia os efeitos desinte- gradores dos mercados sobre as comunidades cria ('entrenching') dominação dentro e entre elas; mas o mesmo é verdadeiro para os outros dois termos. Mercantilização pode realmente ter efeitos negativos realçados por Polanyi. Mas, (...) pode também ter efeitos positivos na medida em que as proteções que desintegra sejam opressivas, como por exemplo quando o mercado de bens de consumo é introduzido em economias geridas burocraticamente ou quando os mercados de trabalho se abrem àqueles que eram involuntariamente deles excluídos. Não menos importante, a emancipação não é imune à ambivalência, já que ela produz não apenas libertação mas também condiciona a fabricação das solidariedades existentes" (Fraser, 2013: 5).

\section{Rebeliões de classe média?}

Olhando para Portugal e Brasil, os contrastes são flagrantes a diversos níveis. Se no caso português o principal móbil da contestação social se ficou a dever à perda de direitos e de poder econômico, ao rápido desmoronar de expectativas, estatutos e condições profissionais que degradaram as condições de vida e de trabalho de amplos setores da população (e em especial das classes médias assalariadas), já no caso brasileiro passou-se um pouco o processo inverso. Isto é, uma evolução positiva do poder de compra, com incrementos na formalização e na segurança no emprego, melhorias na educação e nos programas sociais, etc. - porém, a explicação sociológica destes fenômenos não pode limitar-se a um diagnóstico de conjuntura nem circunscrever-se a uma abordagem de mera "análise política". Embora a variável política seja fundamental, sobretudo se entendermos a "politica" no seu sentido mais profundo, importa estender a reflexão ao campo da cultura, às dinâmicas de grupo e às lógicas de estruturação identitária, a fim de tentar de mostrar como tais elementos se conjugam entre si para se reverterem em ação política.

Desde a década de 1990 que, com a globalização económica e a força crescente do neoliberalismo, o modelo europeu e o Estado social vinham sendo postos em causa, atingindo em primeiro lugar os direitos laborais. $O$ aumento do desemprego, os contratos precários, a subida de impostos, o congelamento de carreiras 
e salários na função pública, a privatização de serviços e de património público, as medidas de contenção impostas na saúde, na educação, na ciência, etc., etc., já há muito vinham sendo denunciadas como um retrocesso nas conquistas da democracia ${ }^{10}, \mathrm{e}$, por isso, grande parte dos portugueses as vinham contestando, mesmo antes da chegada da crise mais violenta.

Mas foi sobretudo nos anos da austeridade que a conflitualidade social mais se acentuou. Entre 2010 e 2012 ocorreram em Portugal 384 greves envolvendo cerca de 224.500 trabalhadores (apenas no setor privado) ${ }^{11}$. A intensidade do descontentamento disparou sobretudo durante a vigência do programa de resgate - assinado pelos três partidos do arco do poder, PS, PSD e CDS - que impôs aos portugueses este modelo de "sociedade da austeridade" (Ferreira, 2012). Muito embora os movimentos sociais "inorgânicos" obedeçam a uma lógica que os afasta do campo sindical, não se deve, todavia, minimizar a importância do sindicalismo na resistência da "sociedade civil" contra as políticas de austeridade (Estanque e Costa, 2012). Quer isto dizer que a tensão existente entre esses dois mundos não invalida a influência e contaminação recíproca entre eles.

\footnotetext{
${ }^{10}$ No Relatório das Crises e das Alternativas, elaborado por uma equipa do CES, sintetiza-se a situação do país no período anterior à crise nos seguintes termos: "a liberalização e a privatização foram acompanhadas e legitimadas por uma modernização dos padrões de consumo, apesar de tudo desigual, fomentada pelo endividamento entre os grupos mais desafogados, e pela manutenção, e até reforço seletivo, de alguns dos pilares fundamentais do Estado social, mesmo que ainda longe dos padrões europeus; o modelo de capitalismo que o Euro reforçou é cada dia mais incompatível com o Estado social, sendo a quadruplicação do desemprego desde 1999 uma dos principais expressões dessa incompatibilidade, e são agora poderosas as forças sociais nacionais e europeias que a querem resolver através da fragilização do Estado social, da redução do salário direto e indireto, em vez de se desbloquear a possibilidade de modernizar a economia, o que requereria outro enquadramento europeu, com outros instrumentos de política económica que permitissem que fossem outras as variáveis de ajustamento" (veja-se o citado Relatório - Capítulo 1 , de autoria de José Reis, João Rodrigues, J. M. Castro Caldas. Coimbra, CES, 2013).
}

\footnotetext{
11 Valores referentes apenas ao setor privado. Não existem dados sistemáticos das greves do setor público, mas a informação parcelar disponibilizada pela Direção Geral da Administração e do Emprego Público (DGAEP, 2014), de 2007 em diante, revela que para esse ano existem registros de três greves abrangendo trabalhadores da administração direta e indireta do Estado, num total de 58311 grevistas, isto é, mais do dobro do registo para o mesmo ano de todo o setor privado.
}

No 12 de Março de 2011 ninguém esperava tanta afluência à primeira grande manifestação da chamada "Geração à Rasca"12. O descontentamento face aos partidos e a democracia representativa era bem visível: "precários nos querem, rebeldes nos terão!»; "queremos as nossas vidas!»; "roubo do salário!»; "o país está à rasca!»; "economia rasca, basta!» «precários não são otários!»; "o povo unido não precisa de partido!»; «rasca é a precariedade»; «não me obriguem a emigrar»; "eu quero ser feliz»; «quem elegeu os mercados?», entre muitos outros, foram alguns dos slogans gritados em Lisboa e no Porto. Um jornal do dia afirmava: “Cartazes com as palavras 'flexitanga' e cravos vermelhos também marcam o protesto. (...) as imagens das televisões mostram um mar de gente na Avenida da Liberdade" (jornal Expresso, 12/03/2011). Em Lisboa a organização indicou a presença de cerca de 200 mil manifestantes e no Porto 80 mil.

Esse foi um momento alto da rebelião social em Portugal. Muitos garantiram que esta foi a maior manifestação desde o 1 de Maio de 1974, a pós a Revolução do Cravos. Representou um momento de viragem em que o campo sindical deixou de ter o exclusivo da luta social e laboral, e por isso marcou momentaneamente o debate público. Dois meses depois os Indignados e as Acampadas da Democracya Real Já, na Puerta del Sol em Madrid - Espanha, transmitiram mensagens de conteúdo semelhante e não deixaram de invocar o exemplo português; e logo depois a onda global de contestação em torno do movimento Occupy Wall Street, centrado em Nova lorque mas que teve uma influência mundial. Em Portugal, pode resumir-se este ciclo, por ordem cronológica: o 15 de outubro de 2011

\footnotetext{
${ }^{12}$ No português de Portugal, sobretudo no vernáculo popular, "à rasca" significa "aflito", que "não aguenta mais" (pode usar-se no caso de necessidades fisiológicas), enquanto o termo "rasca" significa de baixa qualidade, um produto barato, uma condição frágil e pobre. Nos finais da década de 1980, na sequência de uma manifestação de adolescentes, estudantes do ensino médio que protestavam junto do Parlamento contra a reintrodução de exames nacionais, e perante uma cena de exibição pública dos traseiros dos jovens com frases contra a ministra da Educação da época, Vicente Jorge Silva cunhou em título de artigo de opinião o termo "Geração rasca" referindo-se ao que considerou a ausência de valores e a "falta de educação" dessa geração. Assim, a designação Geração à Rasca foi uma espécie de "resposta" da geração dos anos 2000, para exprimir a sua condição precária e os problemas de uma geração com um futuro tão incerto e inquietante.
} 
(Dia de Ação Global), a greve geral de 24 de novembro de 2011 (organizada conjuntamente pela CGTP e pela UGT), as concentrações de 12 de maio de 2012 (Primavera Global), o 15 de setembro de 2012 (Que se Lixe a Troika), o 13 de outubro de 2012 (protestos culturais do movimento de artistas ligados ao Que se Lixe a Troika) e a greve geral com dimensão europeia de 14 de novembro de 2012 (que aconteceu em Portugal, Grécia, Espanha, Malta e Chipre); em 2013 a manifestação do 3 de março (sob o lema da famosa canção Grândola Vila Morena, o Povo é Quem mais Ordena). ao que se seguiu uma vaga de ações promovidas por grupos de jovens organizados, as chamadas "grandoladas", que incluíram iniciativas de boicote a atos oficiais com a presença de representantes do Governo em que o público interrompia os discursos com a referida canção cantada em coro ou com gargalhadas coletivas destinadas a atrapalhar a fala desses personagens (onde o ex-ministro Miguel Relvas foi o alvo privilegiado).

No caso do Brasil, as manifestações de junho de 2013 tiveram, como é evidente, uma base multicausal, remetendo para forças e conexões situadas em diferentes dimensões, do contexto local às escalas estadual, nacional e global. No início daquele mês, a situação na cidade de São Paulo (daqui por diante designada por SP) começou a degradar-se quando, na sequência da decisão das empresas de transportes (naturalmente em sintonia com a Prefeitura) de aumentar o custo dos transportes urbanos (de $\mathrm{R} \$ 3,00$ para $R \$ 3,20$ ), os jovens do Movimento Passe Livre (MPL) $)^{13}$ convocaram manifestações para o centro da cidade contra essa medida, reunindo no início umas escassas centenas de pessoas. O efeito imediato começou por ser a violência policial enquadrada por declarações das autoridades locais, seguidas pela imprensa mainstream, que, como de costume, acusavam os manifestantes de "vândalos" e ameaçaram não ceder. Esses dois fatores - a violência e as infelizes declarações, quer do Prefeito (Fernando Haddad/ PT) quer do Governador do estado (Geraldo Alckmin/ PSDB), num contexto de início da Copa das Confederações (que decorreu no Brasil neste período) e tendo

\footnotetext{
${ }^{13}$ Movimento iniciado no Fórum Social Mundial de Porto Alegre, em 2005.
}

em fundo os faraónicos investimentos na construção de estádios de futebol para a Copa 2014 já vinham acicatando o descontentamento popular - constituíram os detonadores iniciais dos protestos que varreram o Brasil nos meses de junho-julho de 2013. Das reivindicações do MPL rapidamente se evoluiu para a luta contra a "corrupção", a exigência de uma "reforma política", e de sistemas de saúde e de educação públicas de qualidade, isto é, saúde e educação "padrão FIFA", como se gritou nas ruas.

Com base em algumas pesquisas de opinião efetuadas no decurso dos acontecimentos ou no período imediato foi possível caracterizar o perfil dos manifestantes. Naturalmente que levantamentos de massas com a magnitude dos que ocorreram no Brasil não se explicam facilmente e as ciências sociais demoram a elaborar as teorias e as análises adequadas para interpretar o real, sobretudo quando se trata de fenómenos que transportam elementos de novidade, como parece ter sido o caso. As motivações que levaram às ruas esses milhões ${ }^{14}$ de brasileiros durante os "levantes de junho", além de serem muito diversas, foram evoluindo ao longo do tempo, como de resto os posicionamentos dos diferentes atores sociais, alguns deles invertendo completamente as suas posições de um dia para o outro, como abaixo se verá. Os próprios participantes quando inquiridos na própria hora das manifestações revelaram as principais razões da contestação: 1) o aumento do preço dos transportes públicos; 2) a degradação do sistema político; e 3) a ineficiência das políticas públicas nas áreas da saúde e da educação ${ }^{15}$, sendo que

\footnotetext{
${ }^{14}$ Calcula-se que no mês de junho participaram nas manifestações cerca de 3 milhões de pessoas, embora estas medições sejam sempre controversas e arbitrárias.

${ }^{15}$ Vale a pena lembrar que São Paulo é uma cidade com cerca de 12 milhões de habitantes, que o problema dos transportes públicos é um dos mais sentidos pela população, sobretudo a que tem de os utilizar diariamente. Muito observadores apontam o caos urbano como uma autêntica tragédia, muito embora o aumento do volume de automóveis seja também resultado do crescente poder aquisitivo da classe trabalhadora. Em artigo de Delfim Neto, publicado na Carta Capital de 3 de julho de 2013, recordava-se a este propósito uma pesquisa realizada 3 anos antes onde se concluíra que "(...) mais de 1 milhão de indivíduos se obrigam a ir e voltar de casa para o trabalho a pé, duas, três e até quatro horas, diariamente: a maior parte por não poder pagar o preço das passagens e também porque, mesmo pagando, o tempo gasto não seria muito diferente. São Paulo já era um inferno! Até quando tal ordem de coisas seria suportável?" (Carta Capital n 751, 3/06/2013, p. 30)
} 
alguns destes temas foram ganhando importância à medida que os protestos se repetiam e se alastravam a todas as capitais.

$\mathrm{O}$ fato de não ter existido nem liderança nem pretensões vanguardistas ou "revolucionárias" não diminui o impacto da ação coletiva enquanto expressão de uma "desobediência civil" de um povo saturado de falsas promessas que simplesmente ambiciona bem-estar, justiça social e oportunidades. Na sociedade, o todo é mais do que a soma das partes, pelo que, além dos interesses individualistas deste ou daquele setor, o que esteve em causa no Brasil foi, acima de tudo, a luta por uma sociedade onde cada um seja reconhecido pelo seu mérito. Se o objetivo político do Governo está em sintonia com esse desígnio, seria ótimo se soubesse aproveitar o impulso oferecido por quem esteve nas ruas. Isso mesmo estaria, de resto, em coerência com o que afirmou a Presidente Dilma Rousseff quando reconheceu, em declaração solene transmitida nas televisões, que as manifestações "mostraram a força da nossa democracia e o desejo da juventude fazer o Brasil avançar. Se aproveitarmos bem o impulso dessa nova energia política, poderemos fazer melhor e mais rápido muita coisa que o Brasil ainda não conseguiu realizar (...)" (Pronunciamento da Presidente Dilma Rousseff no dia 21/06/2013 - TV Globo).

Apesar disso, o que se verificou após o fecho deste ciclo de rebeliões foi a quebra abrupta de confiança nas instituições e atores sociais do Brasil, o que pode ser conferido comparando os resultados de 2012 com os de julho de 2013. De acordo com os estudos de opinião que tenho vindo a citar, a queda dos níveis de aprovação incidiu sobretudo nos seguintes itens: Presidência da República - de $63 \%$ para $42 \%$ de aprovação; sistema público de saúde - de $42 \%$ para $32 \%$; Governo Federal - 53\% para 41\%; Congresso Nacional - 36\% para 29\%; sindicatos - $44 \%$ para 37\% (IBOPE, 31/7/2013).

\section{Conclusões}

Como pudemos observar, a juventude e a precariedade foram elementos presentes nas mobilizações ao longo deste período, tanto nas lutas dos precários em Portugal e no sul da Europa, como nas sublevações de junho de 2013 no Brasil, embora neste caso houvesse poucas referências expressas à questão laboral. Uma juventude escolarizada e muito familiarizada com os novos meios de comunicação por satélite, e que, segundo os critérios do rendimento e da escolaridade, pertence aos estratos intermédios da estratificação social ou, pelo menos, encontra-se no início de um percurso, talvez no primeiro degrau de uma expectável subida da escada social. Por isso, os seus padrões de gosto, subjetividades e orientações dirigem-se a um horizonte de classe média.

No que se refere à materialidade das relações imateriais, pode dizer-se o seguinte: as comunidades de convívio e de proximidade física tendem, nos dias de hoje, a misturar-se cada vez mais com as redes de comunicação virtuais, em que o uso permanente do hipod, dos tablets, dos computadores ou dos celulares funcionam como teias de significado e grupos de identificação - em parte reais e em parte fictícios - e de "pertença", substituindo-se ou complementando os laços de sociabilidade primária. As ligações à redes virtuais são simultaneamente fatores de integração na coletividade e veículos de afirmação e performance pessoal, onde o "eu" construído e projetado no "outro virtual" se confunde e readapta conforme a máscara que melhor se ajuste a cada esquina da ampla comunidade virtual-real. Estar na manif é tão importante como o ato de divulgar a foto no Facebook com o cartaz ou o disfarce mais apropriado para enfrentar a ameaça policial. As ruas e praças de São Paulo e do Rio de Janeiro (entre muitas outras cidades) foram palcos privilegiados dessas lutas, simultaneamente sociopolíticas, egocentradas, solidaristas e narcisistas. E é justamente sob essa natureza híbrida que se vêm tecendo as novas modalidades de intervenção coletiva e individual e, de certo modo, a nova esfera pública do século XXI.

Essa mesma ambivalência foi detetada tanto no Brasil como nas maiores manifestações em Portugal (e por exemplo nos Indignados em Espanha), isto é, o discurso e as atitudes coletivistas e emancipatórias surgem lado a lado com os slogans mais individualistas ("eu quero ser feliz") e as exigências de mais democracia surgem lado a lado com a linguagem "anti-política" e de repúdio aos valores e aos agentes institucionais da democracia ("o povo unido não precisa de partido!"). São sem dúvida sinais das novas linhas 
de complexidade, mas também, sobretudo no caso do Brasil, da crescente consciência social com que se debatem as gerações que cresceram com a democracia e à sombra dela exigem ver cumpridos os direitos, as oportunidades e a dignidade que nunca tiveram. No caso de Portugal, por seu turno, as camadas descontentes exprimiram a frustração e o desespero de quem já teve direitos consagrados mas que se confronta na atualidade com a sua supressão por exigência do poder económico, das medidas de austeridade e de um poder político desacreditado (que, em período de crise, transcendeu a própria soberania e a legitimidade democrática). Em qualquer dos exemplos referidos as dinâmicas de protesto e de mobilização coletiva parecem transportar, mais do que um programa político ou uma orientação ideológica clara, as aspirações ou a frustração estimuladas por um ethos de classe média que se sentiu agredido e defraudado nas suas expectativas. Em todo o caso, cada vez mais, os impactes políticos das sublevações de massas transcendem sempre as intenções dos seus mentores e muitas vezes persistem muito para além dos seus efeitos imediatos (mesmo que latentes e adormecidos por algum tempo).

\section{Referências bibliográficas}

Arcary, Valério (2013), "Até onde vamos aguentar?", Entrevista publicada no Blogue de Leituras, em 30 de outubro de 2013. in

Barker, Colin (2008), "Some reflections on student movements of 1960s and early 1970s", Revista Crítica de Ciências Sociais, 81, 43-91.

Bourdieu, Pierre; Jean-Claude Passeron (1978), A Reprodução: elementos para uma teoria do sistema de ensino. Lisboa: Editorial Vega.

Bourdieu, Pierre (1979), La Distinction; critique sociale du jugement. Paris: Seuil.

Castells, Manuel (2013), Redes de Indignação e Esperança. Movimentos sociais na era da Internet. Rio de Janeiro: Zahar editores.

Eder, Klaus (2001), "A classe social tem importância no estudo dos movimentos sociais?", Revista Brasileira de Ciências Sociais, vol. 16 (46), 5-27.

Estanque, Elísio (2003), "O efeito classe média desigualdades e oportunidades no limiar do século XXI", in Cabral, M. V., J. Vala e A. Freire (orgs.),
Percepções e avaliações das desigualdades e da justiça em Portugal numa perspectiva comparada. Lisboa: ICS, 69-105.

Estanque, Elísio (2012), A Classe Média. Ascensão e Declínio. Lisboa: Fundação Francisco Manuel dos Santos/Relógio d'Água.

Estanque, Elísio; Rui Bebiano (2007), Do Activismo à Indiferença - movimentos estudantis em Coimbra. Lisboa: ICS.

Estanque, Elísio; Costa, Hermes Augusto; Soeiro, José (2013), "The New Global Cycle of Protest and the Portuguese Case", Journal of Social Science Education, 12(1), 31-40.

Ferreira, António Casimiro (2012), Sociedade da austeridade e direito do trabalho de exceção. Porto: Vida Económica.

Fraser, Nancy (2013), "A triple movement? Parsing the politics after Polanyi”, New Left Review, 81.

Giovanopoulos, Christos \& Dalakoglou, Dimitris (2011), "From ruptures to eruption: a genealogy of the December 2008 revolt in Greece", in Vradis, Antonis and Dimitis Dalakoglou (eds.), Revolt and Crisis in Greece: between a Present Yet to Pass and a Future Still to Come. London: AK Press \& Occupied London, p. 91-114.

Maravall, José Maria (1972), La Sociologia de lo Posible. Madrid: Ediciones siglo Veinteuno de España.

Nobre, Marcos (2013), Entrevista ao Jornal da Unicamp, 28 de julho de 2013.

Parkin, Frank (1968), Middle Class Radicalism. Manchester: Manchester University Press.

Pochmann, Márcio (2014), O Mito da Grande Classe Média. Capitalismo e Estrutura Social. São Paulo: Boitempo.

Tocqueville, Alexis de (1988), De La Democracie en Amérique, in M. Braga da Cruz, Teorias Sociológicas. I Vol. - Os fundadores e os clássicos. Lisboa: Fundação Calouste Gulbenkian.

Wright, Erik Olin (1989), Classes. Londres: Verso.

Žižek, Slavoj (2013), "Políticas do paraíso", Cidades Rebeldes: passe livre e as manifestações que tomaram as ruas do Brasil. São Paulo: Boitempo/ Carta Maior, pp.101-108. 